\title{
Effects of Aging on Compressive Strength of Two Resin-Reinforced Glass lonomers: An In-Vitro Study
}

\section{Emami Arjomand ${ }^{1}$, MH Eghlim ${ }^{2}$, SH Jalalian*3॰ ${ }^{*}$ M Mirzakhani ${ }^{1}$,} A Mahavi

1-Assistant Professor, Restorative Department, Faculty of Dentistry, Tehran Medical Science, Islamic Azad University

, Tehran , Iran

2-Dentist

3-Assistant Professor, Restorative Department, Faculty of Dentistry, Member of Dental Material Research Center , Tehran Medical Science, Islamic Azad University,Tehran, Iran

\section{ARTICLE INFO \\ Article History \\ Received: May 2019 \\ Accepted: Apr 2019 \\ ePublished: Jun 2019}

\section{Corresponding author:}

SH Jalalian,Assistant Professor, Restorative Department, Faculty of Dentistry , Member of Dental Material Research Center, Tehran Medical Science, Islamic Azad University, Tehran, Iran Email: shahriar.jalalian@yahoo. com

\begin{abstract}
Background and Aim:Although the physical properties of modern glass ionomers have been extensively reported, few studies have examined how these parameters change with age. This experimental study aimed to investigate the effect of aging on the compressive strength of resin-reinforced glass ionomers.

Materials and Methods: Two glass ionomers (Fuji IX GP Fast, GC, Japan, and Ketac Universal, 3M, USA) and one composite resin (control; Filtek P60, 3M, USA) were chosen for this study. Both glass ionomers were encapsulated and mixed using an amalgamator and were applied using an appropriate applicator. Forty cylindrical $(4 \times 6$ $\mathrm{mm} 2$ ) samples were made of each material and subsequently incubated at $37^{\circ} \mathrm{C}$ with $95 \pm 5 \%$ humidity. Twenty samples from each material were then randomly selected to undergo aging in a thermocycling machine using 1000 cycles (between $5-55^{\circ} \mathrm{C}$ ). The compressive strength of the samples was then measured using a universal testing machine. One-way analysis of variance (ANOVA) and post-hoc Tuckey's test were used for data analysis.

Results: The aging process (thermocycling) caused a significant increase in the compressive strength of all three materials. Overall, Ketac Universal displayed higher compressive strength with an average value of $271.1120 \pm 15.4387 \mathrm{MPa}$ and $248.6910 \pm 15.10716 \mathrm{MPa}$ with and without aging, respectively, compared to Fuji IX GP and Filtek P60.

Conclusion: The aging process increases the compressive strength of glass ionomers and composites; however, even with aging, modern glass ionomers still struggle to achieve compressive strength values close to those feasible with composite resin. It is therefore essential to use these materials in non-stress-bearing areas.

Keywords: Aging, Compressive Strength, Glass Ionomer
\end{abstract}

J Res Dent Maxillofac Sci 2019;4(3):15-20. DOI: 10.29252/jrdms.4.3.15

\section{Introduction:}

Glass ionomers play an important role in modern dentistry, often used as a base or a liner but also as a restorative material for non-carious cervical lesions as well as an adhesive for orthodontic brackets or as a fissure sealant. ${ }^{(1)}$ As most clinicians move away from amalgam, aesthetic dental materials are becoming the norm..$^{(2)}$
However, until recently, most researchers believed that as far as survival and failure rates are concerned, composites are still superior to glass ionomers concerning posterior restorations. ${ }^{(3)}$ This is in contrast to a recent study that claimed that resin-modified glass ionomers have a survival rate as favorable as that of amalgam and composite restorations. ${ }^{(4)}$ 
Furthermore, in a recent clinical trial, Molina et al claimed that high viscosity glass ionomers have a better three-year survival rate than composites. ${ }^{(5)}$ In another six-year clinical study, the authors evaluated resin-reinforced glass ionomers in terms of their clinical performance and suggested that their performance is acceptable concerning posterior restorations. ${ }^{(6)}$ These new developments alongside the introduction of a whole new generation of glass ionomers by manufacturers warrant further investigation on the application and survival of such materials in the clinic.

Restoration survival is affected by many factors including adhesive, mechanical, and mixing factors alongside many others. ${ }^{(2)}$ One such property is compressive strength, deemed to be an important factor in the long-term survival of restorations. ${ }^{(7)}$ As aging can have a profound effect on the compressive strength of glass ionomers, it is imperative to study its effect on the compressive strength of novel glass ionomers. ${ }^{(8-12)}$ Although the physical properties of modern glass ionomers have been extensively reported, few studies have examined how these parameters change with age. ${ }^{(13)}$ This study aimed to assess the effect of aging on the compressive strength of two glass ionomer restorative materials with a composite resin as a control.

\section{Materials and Methods:}

In this in-vitro experimental study, the compressive strength of two resin-reinforced glass ionomers (Fuji IX GP Fast, GC, Japan) and (Ketac Universal, 3M ESPE, St. Paul, MN, USA) and one light-cure composite resin (Filtek P60, 3M ESPE, St. Paul, MN, USA) was measured (Table 1).

Table 1: Product information

\begin{tabular}{ccccc}
\hline Product & Component & Manufacturer & Shade & Lot no. \\
\hline $\begin{array}{c}\text { Ketac } \\
\text { Universal }\end{array}$ & GI & 3M ESPE & A3 & 4115149 \\
\hline $\begin{array}{c}\text { Fuji IX GP } \\
\text { Fast }\end{array}$ & GI & GC Europe & A3 & $180615 \mathrm{~A}$ \\
\hline Filtek P60 & Composite & 3M ESPE & A3 & N942757 \\
\hline
\end{tabular}

$\mathrm{GI}=$ Glass Ionomer
Both glass ionomers were encapsulated. In total, 120 specimens were prepared (40 specimens from each material). These specimens were fabricated using a cylindrical polyetheretherketone (PEEK) mold with a diameter of $4 \mathrm{~mm}$ and a height of 6 $\mathrm{mm}$ from plastic caps of $27 \mathrm{G}$ syringes (Figure 1).

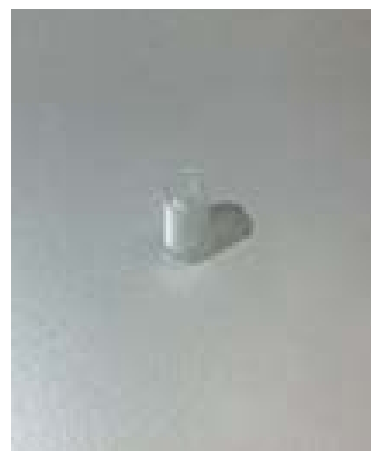

Figure 1. Polyetheretherketone (PEEK) mold

The glass ionomer capsules were first placed in an amalgamator (Silamat S5, Ivoclar Vivadent, Amherst, NY, USA) (Figure 2).

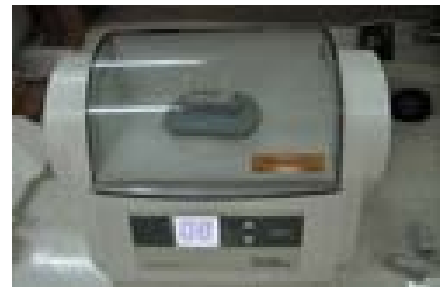

Figure2. Amalgamator (Silamat S5, Ivoclar Vivadent)

according to the manufacturer's instructions for each respective glass ionomer and then transferred to the molds using their respective applicators (Figure 3).

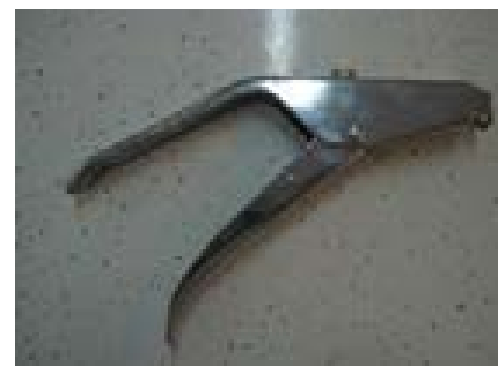

Figure 3. The GC applicator 
As for the composite, the same light-cure device (Bluephase C8, Ivoclar Vivadent, Schaan, Liechtenstein) was used for all specimens (1200 $\mathrm{mW} / \mathrm{cm} 2$ ) (Figure 4).

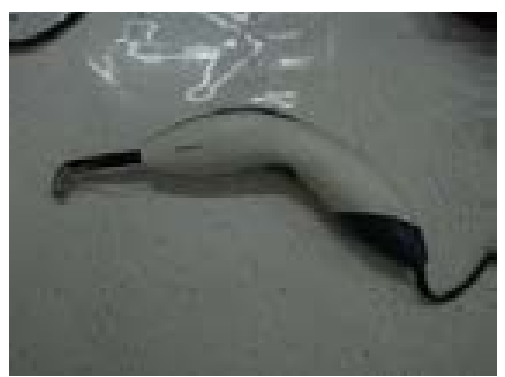

Figure 4. Bluephase light-curing device

The light-cure device was tested using a radiometer (Bluephase meter II, Ivoclar Vivadent, Schaan, Liechtenstein) to ensure that the light intensity was constant $(1200 \mathrm{~mW} /$ $\mathrm{cm} 2$ ) throughout the experiment. All specimens were cured from all sides at a distance of 0.5 $\mathrm{mm}$ for 40 seconds. After the setting reaction, all specimens were polished using a mediumgrit FlexiDisc (Cosmedent, USA) latched onto a contra-angle handpiece (COXO, China) at 25000 revolutions per minute (rpm). All samples were subsequently checked for crack, and if positive, were excluded from the study.

The samples were then stored in deionized water at $37^{\circ} \mathrm{C}$ with $95 \pm 5 \%$ humidity for 24 hours (Figure 5).

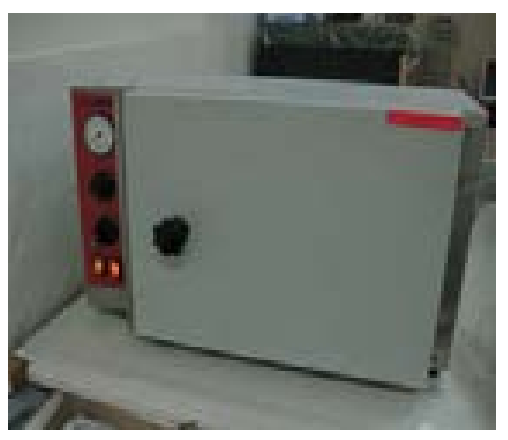

Figure 5. The incubator
The specimens made from each material $(n=40)$ were then randomly assigned to two groups, one of which would undergo aging while the other was tested for compressive strength without any additional step. During the aging process, using a thermocycler (Dorsa apparatus, Tehran, Iran) (Figure 6), the samples were alternatively immersed in water baths of $5^{\circ} \mathrm{C}$ and $55^{\circ} \mathrm{C}$. The dwell time in each water bath was 15 seconds with a transfer time of 10 seconds for 1000 cycles.

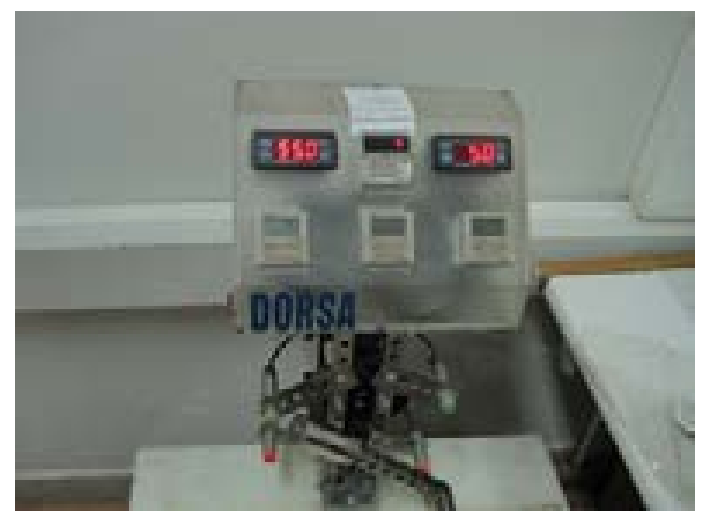

Figure 6. Termocycling machine (Dorsa, Tehran, Iran)

All Specimens were then loaded and tested either after 24-hour water storage or after thermocycling, depending on their respective groups, using a universal testing machine (Santam 20, Tehran, Iran) at a crosshead speed of $1 \mathrm{~mm} /$ minute (Figures 7 to 9).

Statistical analysis was performed using one-way analysis of variance (ANOVA) followed by Tukey's test for intergroup analysis.

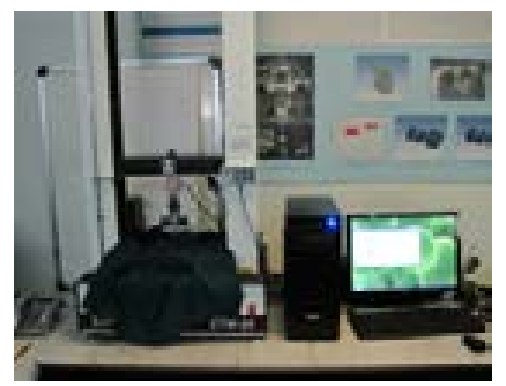

Figure 7. Santam-20 universal testing machine 


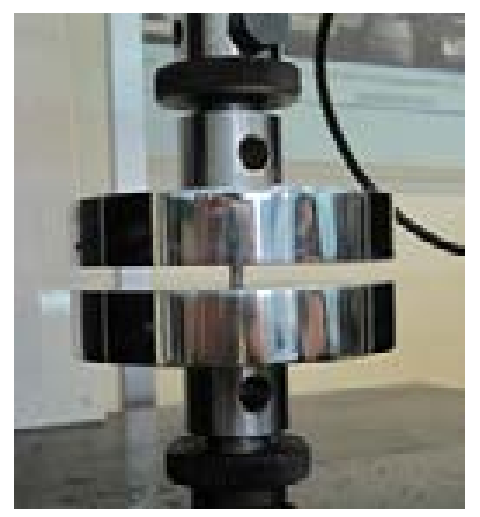

Figure 8. A specimen in the universal testing machine

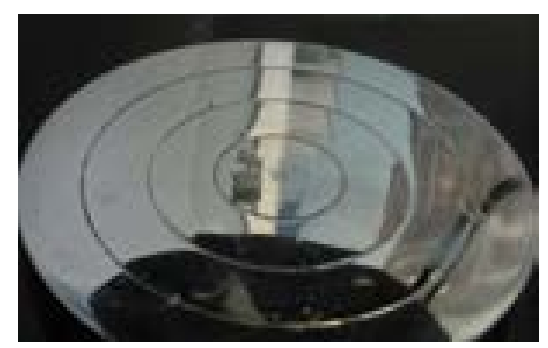

Figure 9. A fractured sample

\section{Results}

The mean and standard deviation (SD) of compressive strength ( $\mathrm{MPa}$ ) and their corresponding P-values are listed in Table 2.

Table 2: Mean and standard deviation (SD) of compressive strength (MPa) in the studied groups

\begin{tabular}{|c|c|c|c|}
\hline $\begin{array}{r}\text { Compressive } \\
\text { strength }\end{array}$ & $\begin{array}{l}\text { With aging } \\
\text { Mean } \pm \text { SD }\end{array}$ & $\begin{array}{c}\text { Without aging } \\
\text { Mean } \pm \text { SD }\end{array}$ & P-value \\
\hline \multicolumn{4}{|l|}{ Material } \\
\hline Ketac Universal 3M & $271.11 \pm 15.43$ & $248.69 \pm 15.10$ & $<0.001$ \\
\hline Fuji IX GP GC & $155.28 \pm 15.92$ & $141.56 \pm 19.07$ & \\
\hline P60 3M & $298.31 \pm 9.09$ & $275.79 \pm 21.77$ & \\
\hline
\end{tabular}

$S D=$ Standard Deviation
Overall, aging caused a significant increase in the compressive strength of all materials. The mean compressive strength for Fuji IX GP Fast was 141.5 $\pm 19 \mathrm{MPa}$ and 155.2 \pm 15.9 $\mathrm{MPa}$ for the non-aged and aged groups, respectively. In comparison, Ketac Universal exhibited a mean compressive strength of $248.6 \pm 15.10716 \mathrm{MPa}$ without aging and $271.1 \pm 15.43874 \mathrm{MPa}$ for the group that underwent aging.

The difference between the compressive strengths of the aged group and the non-aged group was statistically significant for all three materials with Ketac Universal having a higher compressive strength both with and without aging as compared to Fuji IX GP; this difference was statistically significant $(\mathrm{P}<0.001)$. $\mathrm{P} 60$ composite resin showed the highest compressive strength both with and without aging $(\mathrm{P}<0.001)$.

\section{Discussion:}

Compressive strength is one of the most important physical parameters in dental materials science, especially during mastication. Testing of this property is mostly suitable for brittle materials. ${ }^{(14)}$ Physical strength, especially compressive strength, in the first few hours after restoration placement is crucial for resisting masticatory stress and occlusal loading. ${ }^{(15)}$ Although according to Molina et al, a combination of tensile, flexural, and compressive forces are involved in the aforementioned process. ${ }^{(5)}$ It has been proven that storing glass ionomers in different storage media, such as saline, saliva, and water or fruit juice, at different intervals can have a significant effect on the physical properties of such materials, often causing them to improve. ${ }^{(8,16)}$ These results proved that the setting reaction of glass ionomers continues up to three months after restoration placement, thereby increasing the compressive strength of the material. ${ }^{(16)}$ This is in contrast to a study performed by Bali et al, in which the authors claimed that there was no significant relationship between the type of storage media and a change in the compressive strength of 
Fuji IX..$^{(9)}$ The current study used deionized water for storage in the incubator.

In the current study, the compressive strength of two glass ionomers (Fuji IX GP Fast and Ketac Universal) was studied with and without aging. The compressive strength of both materials changed with aging via a thermocycler, this change being an increase in the compressive strength, although this change was more profound for Ketac Universal. This increase in the compressive strength with aging has been attributed to several different mechanisms such as reduced porosity in glass ionomer after some period or the formation of a phosphate network. Whatever the mechanism, it is known that glass ionomers become more brittle and strong (diametral, flexural, and compressive strength) with aging. ${ }^{(13)}$

In a recent study, the high initial compressive strength of Ketac Universal was proven to be due to smaller particles that increase the available surface area for reaction with tartaric acid. ${ }^{(8)}$

One-way ANOVA proved that the difference between the compressive strengths of FUJI IX GP between groups with aging and those without was statistically significant $(\mathrm{P}<0.05)$. This is in line with the results reported by Yap et al, despite the different methodology. ${ }^{(17)}$ It is worth noting that in 2009, Busanello et al reported that there was no significant difference in the compressive strength of FUJI IX at one hour and that at 24 hours after setting. ${ }^{(15)}$

Overall, among the two glass ionomers in this study, whether with aging or without it, Ketac Universal had a significantly higher compressive strength as compared to FUJI IX GP $(\mathrm{P}<0.001)$. This is in accordance with the results reported by Ilie in $2018{ }^{(8)}$ Further studies are needed to verify the superiority of Ketac Universal in terms of its other characteristics, such as flexural strength. Unlike similar studies, the current study used a composite (Filtek P60, 3M) as a control. Several studies have reported that high viscosity glass ionomers can perform as well as composites in posterior restoration. ${ }^{(18)}$ In the current study, there was a significant difference between the compressive strength of P60 and Ketac Universal after aging $(\mathrm{P}<0.001)$. The same results were observed when comparing the compressive strength of FUJI IX GP and P60 after aging $(\mathrm{P}<0.001)$.
In previous studies, a rise in temperature was associated with a rise in the mechanical properties of composite resins; this was attributed to an increase in the rate of polymerization due to the effect of rising temperatures on initiator systems in the composite resin. ${ }^{(19,21)}$ This proves that at least with regards to compressive strength, these glass ionomers do not perform as well as a composite; this, however, does not rule out the application of these materials as restorative materials for Class I restorations as more than one factor is involved in the outcome of such restorations. ${ }^{(5)}$ Moreover, in a clinical situation, polymerization shrinkage will be more profound due to the consequences of the C-factor ${ }^{(22)}$. This, in turn, may affect the compressive strength of composite resins and warrants further clinical research in this field.

\section{Conclusion:}

The results of this study showed that the compressive strength of FUJI IX GP Fast and Ketac Universal increases with aging, these values being higher with the latter. However, these glass ionomers fail to perform as efficiently as P60 composite resin. Further studies are required to assess and document the way that other properties of glass ionomers change with time.

\section{References:}

1.Mjor IA, Gordan VV. Failure, repair, refurbishing and longevity of restorations. Oper Dent. 2002 Sep-Oct;27(5):528-34.

2.Van Dijken JWV, Pallesen U, Benetti A. A randomized controlled evaluation of posterior resin restorations of an altered resin modified glassionomer cement with claimed bioactivity. Dent Mater. 2019 Feb 1;35(2):335-43.

3.Mickenautsch S, Yengopal V. Failure rate of direct high-viscosity glass-ionomer versus hybrid resin composite restorations in posterior permanent teeth - a systematic review. Open Dent J. 2015 Dec 22;9:438-48.

4.Münevveroğlu AP, Ozsoy A, Ozcan M. Microleakage of high viscosity glass-ionomer and glass-carbomer with and without coating before and after hydrothermal aging. Braz Dent Sci. 2019 Jan 31;22(1):79-87.

5. Molina GF, Cabral RJ, Mazzola I, Lascano LB, Frencken JE. Mechanical performance of encapsulated restorative glass-ionomer cements 
(ART). J Appl Oral Sci. 2013 Jun;21(3):243-9.

6. Türkün LS, Kanik Ö. A Prospective Six-Year Clinical Study Evaluating Reinforced Glass Ionomer Cements with Resin Coating on Posterior Teeth: Quo Vadis? Oper Dent. 2016 Nov/ Dec;41(6):587-98.

7. Friedl K, Hiller KA, Friedl KH. Clinical performance of a new glass ionomer based restoration system: a retrospective cohort study. Dent Mater. 2011 Oct 1;27(10):1031-7.

8. Ilie N. Maturation of restorative glass ionomers with simplified application procedure. J Dent. 2018 Dec;79:46-52.

9. Bali P, Prabhakar AR, Basappa N. An Invitro Comparative Evaluation of Compressive Strength and Antibacterial Activity of Conventional GIC and Hydroxyapatite Reinforced GIC in Different Storage Media. J Clin Diagn Res. 2015 Jul;9(7):ZC51-5.

10. Shetty C, Sadananda V, Hegde MN, Lagisetti AK, Shetty A, Mathew T, et al. Comparative Evaluation of Compressive Strength of Ketac Molar, Zirconomer, and Zirconomer Improved. Sch J Dent Sci. 2017;4(6):259-61.

11. Alzraikat H, Maghaireh GA, Zawaideh FI. Physico-mechanical properties of a nanofilled glass ionomer cement. J Res Med Dent Sci. 2016 Jul 1;4(3):270-4.

12.Zoergiebel J, Ilie N. Evaluation of a conventional glass ionomer cement with new zinc formulation: effect of coating, aging and storage agents. Clin Oral Investig. 2013 Mar 1;17(2):619-26.

13. Nicholson JW. Maturation processes in glassionomer dental cements. Acta Biomater Odontol Scand. 2018;4(1):63-71.

14.Bresciani E, Barata TD, Fagundes TC, Adachi A, Terrin MM, Navarro MF. Compressive and diametral tensile strength of glass ionomer cements. J Appl Oral Sci. 2004 Dec;12(4):344-8.

15. Busanello L, Telles M, Junior WG, Imparato JC, Jacques LB, Mallmann A. Compressive strength of glass ionomer cements used for atraumatic restorative treatment. Rev Odonto Ciênc. 2009;24(3):295-98.

16. McKenzie MA, Linden RW, Nicholson JW. The physical properties of conventional and resin-modified glass-ionomer dental cements stored in saliva, proprietary acidic beverages, saline and water. Biomaterials. 2003 Oct 1;24(22):4063-9.
17. Yap AU, Cheang PH, Chay PL. Mechanical properties of two restorative reinforced glass-ionomer cements. J Oral Rehabil. 2002 Jul;29(7):682-8.

18. Gurgan S, Kutuk ZB, Ergin E, Oztas SS, Cakir FY. Clinical performance of a glass ionomer restorative system: a 6-year evaluation. Clin Oral Investig. 2017 Sep 1;21(7):2335-43.

19.Fan PL, Dennison JB, Powers JM. Properties of conventional and microfilled composites. J Mich Dent Assoc. 1980;62(9):455-57.

Fan PL, Dennison JB, Powers JM. Properties of conventional and microfilled composites. J Mich Dent Assoc. 1980; 62(9): 455-7.

20.Kandil SH, Kamar AA, Shaaban SA, Taymour NM, Morsi SE. Effect of temperature and ageing on the mechanical properties of dental polymeric composite materials. Biomaterials. 1989 Oct $1 ; 10(8): 540-4$.

21.Koosha S, Nematolahi F, Torshabi M, Tabatabaei F, Borzoo Y, Vatandoost AM. In Vitro Cytotoxicity of Two Categories of Dental Cements. J Res Dentomaxillofac Sci. 2016;1(2):28-35.

22.Braga RR, Ballestera RY, Ferracane JL. Factors involved in the development of polymerization shrinkage stress in resin-composites: A systematic review. Dent Mater. 2005;21:962-70.

Please cite this paper as:

Emami Arjomand M, Eghlim Mh, Jalalian Sh, Mirzakhani M, Mahavi A. Effects of Aging on Compressive Strength of Two Resin-Reinforced Glass Ionomers: An In-Vitro Study. J Res Dentomaxillofac Sci. 2019; 4 (3) :15-20. 